\title{
Seeing things from the patients' view: what will it take?
}

Changing medical curriculums, listening to and discussing patient stories, and financial incentives that reward health staff for providing more patient centred care may help, but there are no magic bullets, says Nigel Hawkes

\author{
Nigel Hawkes journalist, London, UK
}

Patient centred care has many evangelists but few practitioners. Doctors aspire to a state of grace in which their practice is truly focused on the individual, not on a passing stranger with a set of symptoms. But time is short, pressures great, and financial ligatures too tight.

So what could be done to advance the ideal a little faster? Can good teaching and training make the difference, or do healthcare professionals, including doctors, need incentives to succeed and sanctions if they fail? How would we even measure success and failure?

One problem is that patient centred care trades under many names, including participatory medicine, shared decision making, and support for self management, all with slightly different meanings. Proponents advance their own labels, diffusing focus and giving the impression of a circle of enthusiasts talking to each other but making a limited impression on the profession as a whole.

\section{Unblinding patients}

Many doctors, of course, claim that they already provide patient centred care. But this claim is hard to sustain given that doctors dominate in clinical encounters and hold most of the cards. A computer screen generally divides patient from practitioner, allowing one party to consult the record while the other remains a "blind" petitioner. Danny Sands, cochair of the US Society for Participatory Medicine, says that the first thing he does when training primary care doctors is to alter this time honoured arrangement. "I look at the screen and I turn it round so that the patient can see it, too," he said.

Many people think that patient centred care is impossible without shared records. "It's fundamental," said Catherine Foot of the King's Fund, lead author of a recent report, People in Control of their own Health and Care. " "The idea that you are not allowed to access information about what is going on inside your body is ridiculous."

Shared records may be necessary but they are not sufficient. Health professionals need to be taught and trained differently, and patients also need to change. Financial and other incentives may help but the greatest incentive to doctors, says Sands, is practising medicine better.

Jagtar Dhanda, head of inclusion at Macmillan Cancer Support, makes the same point. The cancer charity has been involved in training programmes that bring doctors and patients together to design new programmes of care. "There's tension at the start, with doctors on one side of the room and patients on the other, but once you've broken down the barriers you can have a really rich conversation. Health professionals who've been involved become very strong advocates and they go and become champions of the ideas in their own peer networks," he says.

Mohammad Al-Ubaydli, a clinician and information technology specialist who founded Patients Know Best, ${ }^{2}$ a system designed to allow doctors and patients to communicate securely online, says: "Everyone wants to do patient centred care, but on the ground nobody does it. The way we demonstrate it to professionals is to say that it's in their personal interest to put the patient in control of the record. It's a case of saying to the doctors that in your specialty, in this region, at this funding level, the more the patient has control the more you will benefit by saving time, saving money, improving outcomes-and the patient will be happier."

\section{Updated training}

New technology and old ideas about patient centred care are converging. ${ }^{3}$ Ron Hsu of Leicester Medical School, who is using Patients Know Best as an adjunct to undergraduate teaching, says: "It's absurd to have techniques of teaching and training that are based in the 1950s and 60s." He points out that today's students will complete their specialist training in the 2020s. "It's inconceivable that the public by then won't expect electronic communication with their doctors? So why aren't we teaching our students to do it?"

Hsu devised a scheme in which lay volunteers, hiding behind "avatars" to protect their anonymity, communicate by email with groups of students. "I told the volunteers to behave normally not in a standardised way (the usual teaching 
approach)," he says. "That put the volunteers in control, because one of their concerns had been 'Do I have to behave in a certain way?' 'What are the rules and boundaries?' I said there are no boundaries, you can be racist if you want, you can be misogynistic if you want, but the students have to maintain their professionalism throughout."

Richard Thomson, professor of epidemiology and public health at Newcastle Medical School, has developed training programmes for postgraduates to improve their skills in working collaboratively with patients through awareness training and role play. About 600 people have been through the workshops in the past year.

"What we really need to do nationally is to create that appropriate menu of skills in patient centred care and provide access for clinicians to develop their skills.

"What disappoints me is that nationally the main educational providers are not driving this agenda through. The General Medical Council says the right things about being a good doctor, the Royal College of Physicians has appointed a lead fellow in shared decision making - good stuff is happening but it's not sufficiently coordinated."

Dhanda agrees that there is a "lack of alignment" between the different bodies involved. "You've got the General Medical Council, the royal colleges, Health Education England, the NHS Leadership Academy, and so on, but they all have different views and starting positions on what they think leadership and development in this field means."

Thomson says it proved hard to get patient centred care into the undergraduate curriculum at Newcastle, and "Nationally, it's still not really biting on postgraduate training. I can't see that people will struggle to pass royal college membership exams if they're not person oriented."

The Royal College of Physicians expressed support for shared decision making in a position statement published in July 2013. It says that the professional attitudes and skills needed for shared decision making and support for self management needs "to be woven into physician training and assessment."

But in a statement on the college's website, Nick Lewis-Barned, a consultant in diabetes and endocrinology at Northumbria NHS Foundation Trust and the shared decision making clinical fellow, acknowledges patient involvement in the UK lags behind "almost all other developed health systems" including those in the US, New Zealand, and France. ${ }^{5}$

Foot believes that training in motivational interviewing is important. This is a counselling approach, defined as "a collaborative conversation for strengthening a person's own motivation and commitment to change." Doctors can be trained in the technique and Foot says it works. "When you talk to doctors who've been trained to do this they report that it's absolutely transformative," she says. "They go in thinking that they do share the decisions with patients and come out realising they don't."

She is also enthusiastic about "value-based" recruitment policies which Health Education England plans to introduce.

\section{Can incentives help to change practice?}

Many suggestions have been made to encourage patient centred care, from the introduction of points in the Quality and Outcomes Framework, ${ }^{6}$ to the use of extra payments to hospitals under the Commissioning for Quality and Innovation Programme (CQUIN). But Foot has doubts. "A hospital inpatient is affected by every person they see-you can't sum up your experience easily and that makes it hard to incentivise. It's too far-removed from something that you can set a target for."

Robin Hewings, head of policy at Diabetes UK, cites as a positive example the use of local enhanced services payments to encourage general practitioners in Islington to engage in care planning sessions with people on the diabetes register. GPs who have taken part often begin as sceptics but gain in enthusiasm later, he says. "They find it works really well, because what it does is to get people to have a strong sense of ownership of what they need to do. One doctor said: 'I've spent 20 years telling my patients what to do, and now that I've helped them to find the answer themselves, they do it."

In Wolverhampton, patient centred care in diabetes has been encouraged by removing the incentives that often lead to fragmentation of care - principally, the payment by results tariff that encourages hospitals to admit and retain patients. A block contract was placed with Royal Wolverhampton NHS Trust for specialist care and a shared IT system enables specialists to identify people who need specialist attention without a referral from a GP. This is achieved through a central portal that extracts data from general practices and uses a locally developed algorithm to stratify patients by risk as red, amber, or green. This is used to determine how and where a patient should be treated. If a patient falls into the red band specialist treatment can be provided without having to wait for a referral. The trust also delivers community care services, removing another barrier to integration.

In the US, the Centers for Medicare and Medicaid have introduced financial incentives, under the Meaningful Use framework, for doctors to use modern technology, ${ }^{7}$ to communicate with patients, although Sands says there is a lot of resistance to change.

"If doctors don't go with it not only do they not get the financial incentives but over the years they will see a reduction in payments for visits. But I'm not optimistic that doctors are going to change their behaviour as a result of these incentives - they' re doing everything they can to adhere to the regulations without really encompassing the spirit. I've seen companies that offer to communicate with patients electronically so that doctors don't have to."

A different approach is to use professional interactions to drive a change in attitudes. Just as multidisciplinary teams improve quality of care, regular discussions among groups of staff about the human dimensions of care can too. So called Schwartz rounds (named after the Boston based Schwartz Centre for Compassionate Healthcare that devised them) usually take place once a month for an hour at a time, with the first 10-15 minutes taken up by a team telling a patient's story or exploring a theme. The rest of the time is devoted to discussion guided by a facilitator. A King's Fund pilot of Schwartz rounds in two acute trusts in England found that they increased empathy and understanding and resulted in a less hierarchical environment and a culture of openness. ${ }^{8}$ Schwartz rounds, with the support of the Point of Care Foundation, have spread to 87 health organisations across the UK.

Macmillan is a strong supporter of Schwartz rounds and has put money into 35 trusts to implement them. "We see real value in it because the whole idea of reflective practice is so important," says Dhanda. "Health professionals need a safe space to discuss with colleagues when things go wrong and when they go right, and where they don't have to come up with a ten-point plan."

Competing interests: I have read and understood BMJ policy on declaration of interests and have no relevant interests to declare. 
Provenance and peer review: Commissioned; not externally peer reviewed.

1 King's Fund. People in control of their own health and care. 2014. www.kingsfund.org.uk/ publications/people-control-their-own-health-and-care.

2 Al-Ubaydli M. Patients must have control of their own records. BMJ 2012;345:e5575.

3 National Information Board. Personalised health and care 2020. 2014. www.england.nhs. uk/wp-content/uploads/2014/11/nib-report.pdf.

4 Smith R. Teaching medical student online consultation with patients. BMJ blog, 14 February 2014. http://blogs.bmj.com/bmj/2014/02/14/richard-smith-teaching-medical-studentsonline-consultation-with-patients/.
5 Lewis-Barned N. Implementing shared decision-making and support for self-management in the RCP. www.rcplondon.ac.uk/sites/default/files/briefing on shared decision making briefing.pdf.

6 Greenfield G. GPs should be rewarded for patient experience to encourage a person centred NHS. BMJ 2014;348:g6422.

7 Centers for Medicare and Medicaid Services. Meaningful use, stage 1. www.cms.gov/ Regulations-and-Guidance/Legislation/EHRIncentivePrograms/Meaningful Use.html.

Goodrich J. Supporting hospital staff to provide compassionate care: do Schwartz Rounds work in English hospitals? J R Soc Med 2012;105:117-22.

Cite this as: BMJ 2015;350:g7757

(c) BMJ Publishing Group Ltd 2015 